\title{
Currents issues in cardiorespiratory care of patients with post-polio syndrome
}

\author{
Tópicos atuais no tratamento cardiorrespiratório de pacientes com síndrome \\ pós-poliomielite
}

\author{
Marco Orsini1,2,3, Agnaldo J. Lopes ${ }^{1}$, Fernando S. Guimarães ${ }^{1}$, Marcos R. G. Freitas 4 , Osvaldo J. M. \\ Nascimento ${ }^{4}$, Mauricio de Sant'Anna Junior ${ }^{5}$, Pedro Moreira Filho ${ }^{4}$, Stenio Fiorelli2, Ana Carolina A. F. \\ Ferreira ${ }^{4}$, Camila Pupe 4 , Victor H. V. Bastos ${ }^{6}$, Bruno Pessoa ${ }^{4}$, Carlos B. Nogueira ${ }^{4}$, Beny Schmidt 6 , \\ Olivia G. Souza4, Eduardo R Davidovich4', Acary S. B. Oliveira7, Pedro Ribeiro ${ }^{3}$
}

\begin{abstract}
Post-polio syndrome (PPS) is a condition that affects polio survivors years after recovery from an initial acute attack of the poliomyelitis virus. Most often, polio survivors experience a gradual new weakening in muscles that were previously affected by the polio infection. The actual incidence of cardiovascular diseases (CVDs) in individuals suffering from PPS is not known. However, there is a reason to suspect that individuals with PPS might be at increased risk. Method: A search for papers was made in the databases Bireme, Scielo and Pubmed with the following keywords: post polio syndrome, cardiorespiratory and rehabilitation in English, French and Spanish languages. Although we targeted only seek current studies on the topic in question, only the relevant (double-blind, randomized-controlled and consensus articles) were considered. Results and Discussion: Certain features of PPS such as generalized fatigue, generalized and specific muscle weakness, joint and/or muscle pain may result in physical inactivity deconditioning obesity and dyslipidemia. Respiratory difficulties are common and may result in hypoxemia. Conclusion: Only when evaluated and treated promptly, somE patients can obtain the full benefits of the use of respiratory muscles aids as far as quality of life is concerned.
\end{abstract}

Keywords: postpoliomyelitis syndrome; respiration disorders; rehabilitation.

\section{RESUMO}

Síndrome pós-polio (SPP) é uma condição que afeta sobreviventes da poliomielite aguda (PAA), anos após a recuperação de um ataque agudo inicial do vírus. Na maioria das vezes, os sobreviventes da polio começam a apresentar nova paresia gradual nos músculos que foram previamente afetados pela infecção. A incidência real de doenças cardiovasculares (DCV) em indivíduos que sofrem de SPP não é conhecida. Entretanto, há indícios para suspeitar de que sujeitos com SPP podem estar em maior risco. Método: Realizou-se uma busca de artigos nas bases de dados: Bireme,Scielo e Pubmed, utilizando as seguintes palavras-chave:síndrome pós-poliomielite, função cardiorrespiratória e reabilitação, nos idiomas Inglês, Francês e Espanhol. Embora tenhamos selecionado um número expressivo de artigos, somente foram considerados os duplo-cegos, randomizados-controlados, além de consensos. Resultados e Discussão: Certas características da SPP, tais como fadiga muscular, paresia, dor muscular e/ou articulares podem resultar em descondicionamento por inatividade física, além de obesidade e dislipidemia. Dificuldades respiratórias são comuns e podem resultar em hipoxemia. Conclusão: Somente quando avaliados e tratados em tempo hábil, alguns pacientes são capazes de obter os benefícios do uso dos músculos respiratórios auxiliares em termos de qualidade de vida.

Palavras-chave: síndrome pós-poliomielite; transtornos respiratórios; reabilitação.

Neuromuscular diseases (NMDs) can affect anyone at any time. They cause muscle weakness that can affect the heart, breathing, coughing, swallowing, speech, and limbs muscles, all of which cause disability and compromise the quality of life. Previous acute poliomyelitis (PAP) can be defined as an endemic human disease caused by an enterovirus of worldwide distribution, which compromises the anterior horn cells of the spinal cord ${ }^{1,2}$.

\footnotetext{
${ }^{1}$ Centro Universitário Augusto Motta, Programa de Pós-Graduação em Ciências da Reabilitação, Rio de Janeiro RJ, Brasil;

${ }^{2}$ Universidade Severino Sombra, Faculdade de Medicina, Vassouras RJ, Brasil;

${ }^{3}$ Universidade Federal do Rio de Janeiro, Instituto de Psquiatria, Laboratório de Mapeamento Cerebral e EEG, Rio de Janeiro RJ, Brasil;

«Universidade Federal Fluminense, Hospital Universitário Antonio Pedro, Niterói RJ, Brasil;

${ }^{5}$ Instituto Federal de Educação, Ciência e Tecnologia do Rio de Janeiro, Curso de Fisioterapia, Rio de Janeiro RJ, Brasil;

${ }^{6}$ Universidade Federal do Piauí, Parnaíba PI, Brasil;

7 Universidade Federal de São Paulo, Departamento de Neurologia, São Paulo SP, Brasil;

Correspondence: Marco Orsini; Universidade Federal do Rio de Janeiro, Instituto de Psiquiatria, Laboratório de Mapeamento Cerebral e EEG; $22290-140$ Rio de Janeiro RJ, Brasil; E-mail: orsinimarco@hotmail.com

Conflict of interest: There is no conflict of interest to declare.

Received 28 October 2015; Received in final form 11 February 2016; Accepted 06 April 2016.
} 
A new framework for amyotrophy (Figures 1 and 2), unusual fatigue, joint problems, and pain - all with a progressive characteristic, marks the post-polio syndrome (PPS). The prevalence of fatigue is remarkably high, and may contribute significantly to patients' disability and a reduced quality of life. Other possible clinical presentations are the intolerance to cold and cardiorespiratory problems, including sleep apnea. We emphasize that, although there is a broad range of signs and symptoms, its totality is not expressed in all those affected individuals ${ }^{1,2}$.

There is no particular electrodiagnostic test for PPS. Conventional electromyography is unable to distinguish reliably between stable post-polio patients and those with new weakness. However, clinical, electrophysiological evaluation can be useful to document signs of previous motor neuron loss due to PAP, and for excluding other neurological disorders. The PPS diagnosis is supported by new clinical findings and clinical, electrophysiological evidence of PAP ${ }^{3}$.

Patients with PAP might have compromised lung function, irrespectively of shortness of breath. Risk factors such as ventilation at polio-onset and polio-onset after ten years of age can help predict those at risk of respiratory compromise. The measurement of respiratory muscle strength and maximal expiratory pressure (MEP) in particular, can augment the assessment of lung function in this population ${ }^{4}$.

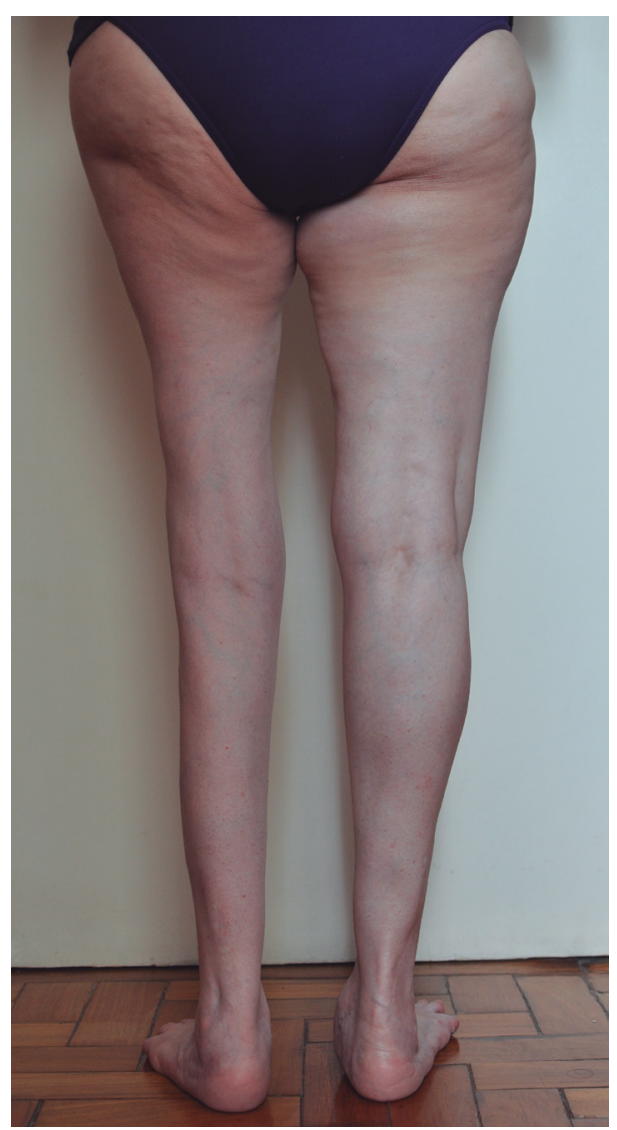

Figure 1. Amyotrophy: posterior view of the left lower limb.

\section{SLEEP DISTURBANCES}

Sleep disorders are common in PPS patients 5 .Their insidious nature may hamper the recognition of these disturbances by patients, family and caregivers ${ }^{6}$. A study reporting nine months of follow up of 21 post-polio syndrome patients was not able to prove significant difference of sleep quality between post-polio syndrome, non-post-polio syndrome and control groups?

Among sleep disorders related to PPS, periodic limb movements (PLM) hypopnea and, specially, obstructive sleep apnea (OSA) are the most frequent ${ }^{5,6,8}$. Breathing disturbances seem to be moreusual during sleep of PPS patients than in general population ${ }^{8}$. There are some signs and symptoms that may alert to the under ventilation, such as: orthopnea, insomnia, anxiety about going to sleep, restless fragmented sleep, morning headaches and worsening mental status ${ }^{6}$.

Prospective study with 60 PPS patients showed that sleep abnormalities was prevalent in $78.3 \%$ of patients. Sleep efficiency decreased in 44 of the 60 patients, ranging from $67.4 \%$ (patients with OSA, using non-invasive ventilation) to $69.5 \%$ (patients not using non-invasive ventilation). This inefficiency is assigned to more than 10 arousals per hour, seep-related disordered breathing, PLM, changes in the different sleep stages and muscle and/or joint pain. Polysomnographic examination demonstrated greater time

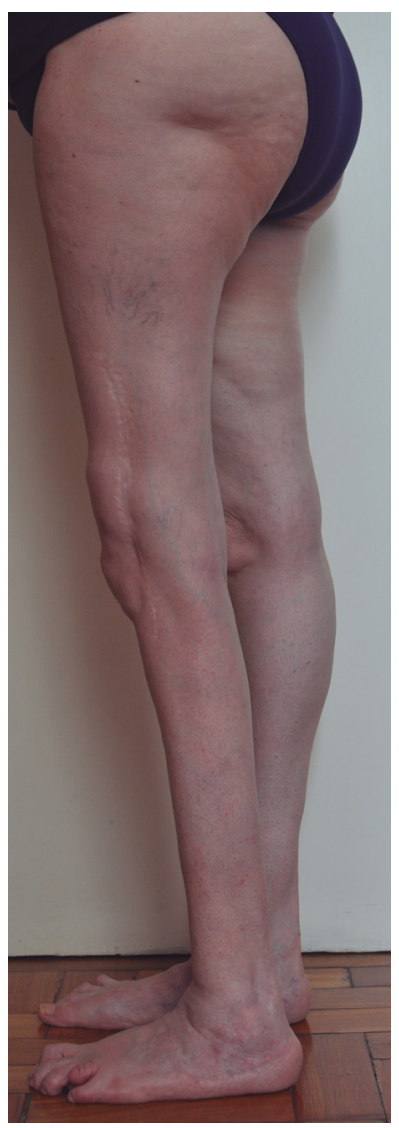

Figure 2. Amyotrophy: Side view of the left lower limb. 
spent in superficial sleep than in deeper stages ${ }^{8}$.This occurrence may be credited to the impairment induced by poliovirus on reticular formation, an area known to mediate initiation of REM sleep ${ }^{8,9}$. The latencies of tone reduction (MTR), sawtooth waves (STW), and REM seemed to be meaningfully higher in the bulbar involvement ${ }^{9}$.

In case of OSA, BiPAP, respiratory physical therapy, as well as, flu vaccines are among the resources indicated ${ }^{6,8,10}$. These sleep disorders may contribute to a cardinal PPS symptom: fatigue $^{5,8,11,12}$. Considering its importance, some approaches were tried to minimize its impact. Modafenil was not superior to placebo in alleviating fatigue or improving quality of life in sample of 36 PPS patients ${ }^{13}$. However, controlled trial demonstrated that transcranial direct current stimulation (tDCS) over the pre-motor areas for fifteen days improved sleep and fatigue symptoms in patients with $\mathrm{PPS}^{13}$.

Generalized fatigue, specific muscle weakness and joint and/or muscle pain may result in physical inactivity - deconditioning, obesity and dyslipidemia. PAP and PPS with respiratory difficulties may develop hypoxemia. Any of these circumstances - deconditioning, obesity, dyslipidemia and hypoxemia - may increase the risk for cardiovascular disease $^{14}$.The safety and the efficacy of training PPS and other NMDs patients were evaluated by some investigators. All of them found that a carefully designed exercise program, which avoided excessive muscle fatigue was able to provide positive results. In general, exercise has to be started very gradually and at a lower level, individually tailored to each's physical status and individual needs. Care should be taken to avoid overuse. Nutritional counseling is also useful ${ }^{15,16}$.

\section{PULMONARY FUNCTION AND RESPIRATORY CARE IN POST-POLIO SYNDROME}

Pulmonary function (PFTs) related to the effects of age-of-onset of the disease has been exhaustively investigated in PPS patients ${ }^{17,18}$. Many different tests and techniques have proved to be helpful in this regard, but disagreement on how best to use these tests still exists. All this effort might be explained due to the difficulty to diagnose respiratory failure from PPS, especially if not suspected ${ }^{17,19}$.

Interestingly, Halstead and Rossi ${ }^{17}$ observed that in patients with PPS, impaired lung function is associated with the age-of-onset (progression for ten years or more), the need for mechanical ventilation during the acute phase of the disease, quadriparesis, and time of exposure to the disease. In another study, Lane et al. ${ }^{20}$ described an association between respiratory dysfunction and the presence of kyphoscoliosis or diaphragmatic paralysis.

Usually, PPS affects the same muscle groups that were affected by the initial onset of the disease. Thus, if respiratory insufficiency was not a feature of the first presentation of polio, it is relatively unlikely to manifest itself during the PPS.
However, the distribution and severity of respiratory muscle involvement in PPS patients is quite variable ${ }^{19}$.

Because of the variable distribution of paresis, there are some patients whose inspiratory and expiratory muscle weaknesses are roughly equal. In others, might predominate expiratory muscle weakness or inspiratory muscle weakness preferentially. There is a tendency for expiratory weakness exceed inspiratory weakness ${ }^{19,21}$.

The principal respiratory manifestation of PPS in the PFTs is a restrictive defect in ventilatory function. It happens due to the weakness of respiratory muscles, which are unable to generate either the intrathoracic vacuum necessary for full inspiration or the positive pressure needed for full expiration. Consequently, this leads to reductions in total lung capacity (TLC), vital capacity (VC), and maximal voluntary ventilation (MVV). Additionally, Lira et al. observed that the MVV was approximately $27 \%$ lower in PPS patients compared to healthy controls $(\mathrm{p}=0.0127)$. In the same study, however, the authors observed that the MVV values were within the normal range when compared with the predicted values for the Brazilian population ${ }^{22}$.

Similar to other neuromuscular diseases, the VC is lower than would be predicted from muscle weakness alone in PPS; this reduction is due in large part to reductions in the compliance of the lung and chest wall. Residual volume is increased in some cases, not because of airway obstruction, but because PPS patients cannot overcome the outward recoil of the chest wall below residual functional capacity ${ }^{23}$.

The relative reduction of inspiratory capacity and expiratory reserve volume provide insight into the relative involvement of inspiratory versus expiratory muscles, respectively. One application of spirometry that can provide helpful diagnostic information is comparing upright and supine VCs in PPS patients suspected of diaphragm weakness; a decline of $25 \%$ or more when patients lie supine is considered an indicator of significant weakness ${ }^{23}$.

Stiffness (reduced compliance) of the lungs and/or chest wall is another possible complication of PPS. The reduction in pulmonary compliance linked to the reduction in lung volumes that is characteristic of the neuromuscular disease. The cause may be microatelectasis, reduced surface tension, alterations in the elastic fibers of the pulmonary interstitium, or a combination of one or more of these factors, each of which may result from habitually low lung volumes ${ }^{23}$.

Other late complications that may be related to PPS are chronic hypoventilation, alterations in central control of breathing, and sleep apnea syndrome. Studies of maximum respiratory pressures confirm that hypercapnia only develops when respiratory muscle strength is considerably reduced. Impairment of the upper respiratory system also can be an important but easily overlooked factor in PPS and warrants investigation when suspected ${ }^{24}$.

Some patients with PPS tend to breathe with a rapid, shallow pattern that compromises their ventilatory function by 
increasing the ratio of dead space to vital volume. When the ventilatory load on the respiratory system is excessive about the ventilatory capacity, patients develop breathlessness, reduced exercise tolerance, and eventually ventilator failure ${ }^{24}$.

In addition to this, Weinberg et al. found that respiratory failure is the limiting factor for exercise in PPS patients with respiratory muscle dysfunction. According to these authors, the extent of lung disease is evident by blood gas values during the exercise test, but not at rest ${ }^{18}$.

The respiratory care approach of post-polio syndrome patients follows the standard recommendations for patients with neuromuscular diseases with few particularities. As expiratory muscle weakness is a common manifestation of illness, manually or mechanically assisted cough can be useful in selected patients aiming to prevent secretion retention ${ }^{25}$.

Moreover, when the inspiratory muscles are significantly compromised, other resources as breath-stacking technique, manual hyperinflation (using a resuscitator bag) and intermittent positive pressure ventilators (volume or pressure controlled modes applied noninvasively by a mouthpiece or mask) can also be used to improve the inspiratory volume prior the forced expiratory maneuver ${ }^{26}$.

In severely compromised patients, both inspiratory and expiratory phases can be enhanced by using the mechanically assisted cough, a device specially designed to improve the cough in neuromuscular diseases. Patients with cough peak flow $<270 \mathrm{~L} / \mathrm{min}$ should be considered eligible for cough peak flow augmentation techniques ${ }^{27}$. Likewise, the pulmonary expansion techniques are also advocated to maintain or improve pulmonary compliance and cough, and to diminish atelectasis ${ }^{28}$.

Some patients might benefit from noninvasive ventilation (NIV). Notably, those with clinical signs and symptoms of respiratory failure and hypoventilation. Additionally, patients with some symptoms such as dyspnea on minor exertion or talking, orthopnea, frequent nocturnal awakenings, excessive daytime sleepiness, daytime fatigue, morning headache, difficulty clearing secretions, apathy, poor appetite, poor concentration or memory) ${ }^{29}$.

The NIV regimen usually starts with nighttime use and during the day as needed. When multiple hourly desaturations below 95\% occur, and home end tidal CO2 (EtCO2) measures over $50 \mathrm{~cm} \mathrm{H} 2 \mathrm{O}$, a trial of nocturnal NIV may help clear symptoms and normalize blood gase ${ }^{28}$.

Almost half of all patients with PPS present with some sleep disturbance, specifically fatigue and excessive daytime sleepiness, headaches, and restless legs syndrome (RLS) ${ }^{30}$. The main clinical findings are hypoventilation, apnea, and hypopnea associated with significant obstructions and desaturation reduced sleep efficiency due to prolonged sleep latencies and high arousal indices ${ }^{8,31}$.

Although overnight EtCO2 provides valuable information concerning nocturnal hypoventilation, it is recommended that suspected sleep dysfunction in neuromuscular disorders be investigated with full-night in-laboratory polysomnography (PSG) ${ }^{32}$. This tool is valuable both for the diagnosis and treatment adequacy, since it allows the noninvasive positive pressure titration to determine an effective level of nocturnal ventilatory support in patients with chronic alveolar hypoventilation, and/or sleep disturbances ${ }^{33}$.

\section{CARDIOLOGIC PROBLEMS AND REHABILITATION IN POST-POLIO SYNDROME}

Cardiovascular diseases have a high incidence and prevalence, progressing to morbidity and mortality outcomes in the general population and should not be ignored in PPS. The frequent exposure to risk factors for cardiovascular diseases, particularly for coronary heart disease (CHD) such as family history of $\mathrm{CHD}$, obesity, diabetes mellitus, smoking, hypertension, increased LDL cholesterol, low HDL cholesterol and dyslipidemia might increase the risk in PPS patients even further ${ }^{14,34}$.

An appropriate stratification of cardiovascular risk for PPS takes into consideration the use of global scores (Framingham, Münster Heart Study, Reynolds etc.). However, the use of coronary artery calcium (CAC) may be an excellent alternative due to its good predictor power for coronary events evidenced in various multivariate analyses being currently an important tool for cardiovascular risk stratification, by subclinical atherosclerosis detection. As it does not require intravenous contrast, the performance of the CAC does not require fasting or any other type of preparation ${ }^{35}$.

Another relevant issue assessing the cardiovascular system of PPS carriers is the performing of echocardiography and electrocardiographic in order to evaluate ventricular function, particularly left ventricle and electrical conduction. Stöllberger et al. ${ }^{36}$ described in a prospective observational study, an increased chance of patients with NMDs to evolve to left ventricular hypertrabeculation/noncompaction (LVHT) being the PPS carriers included in this group. Such condition may result in complex arrhythmias, besides, to predispose patients to sudden death, being in many cases asymptomatic.

It is believed that for the reduction of cardiovascular risk factors in subjects with PPS, it is necessary the guidance on changing habits such as nutritional education. In PPS a changeable and predominant risk factor to an increased chance of developing CHD is a sedentary lifestyle. Changes of the musculoskeletal system in PPS are the main factors for physical inactivity resulting in deconditioning, weight gain, changes in cholesterol and dyslipidemia ${ }^{37,38}$.

Additionally, Nollet et al. ${ }^{37}$ reported a significant reduction in aerobic capacity assessed by spirometry in PPS. This reduction causes limitation in performing activities in submaximal and maximal intensity which results in deterioration of PSS functional capacity, becoming indicated the regular practice of physical exercise. 
Yet, Kriz et al. ${ }^{38}$ showed a significant improvement in individuals with PPS who participated in a 16-week exercise program with frequency of three times a week, with each session lasting 20 minutes using cycle ergometer of the upper limbs. The intensity of the activity was measured by reserve heart rate (70-75\%) using the Karvonen formula and the Borg scale (13-15 points).

Doing so, all subjects underwent ergospirometric evaluation before and after the exercise program. At the end of 20 weeks there was an increase in exercise time performed by the group that practiced the activity, besides an increase in VO2peak, VCO2 and VE in addition to the safety report regarding hemodynamics during the training session, thus proving the benefits of physical activity for people with PPS compared with PSS carriers that do not practice any exercise ${ }^{38}$.

Besides, the study by Dean and Ross ${ }^{39}$ found that an exercise program for six weeks, at an intensity of $55-70 \%$ of maximum heart rate (assessed by average predictive formula), three times a week, may play a significant role in improving endurance, reducing fatigue during the performance of daily life activities.

Aiming the correct prescription of exercise intensity, Voorn et al. described that the anaerobic threshold can be obtained in individuals with PSS following with gold standard for such demand. However, the ergometer used must be the cycle ergometer. In case of the impossibility of obtaining the anaerobic threshold (no ergospirometer) the use of Borg scale seems to be the best alternative ${ }^{40}$.

In order to check cardiovascular risk in individuals with PPS, it is suggested the monitoring of the lipid profile, conducting global scores and CAC. The performing of electrocardiogram and echocardiogram is essential so as to discard possible arrhythmic and/or ventricular dysfunction changes. With regard to the exercise prescription, the results of the electrocardiogram and echocardiogram helped achieve proper stratification of pre-risk exercise, but the exercise tests must also be applied ${ }^{41}$.

Maximum testing should be avoided in PPS due to the fatigue that may be triggered and the activity should be prescribed based on submaximal tests. The six-minute walk test despite being a submaximal intensity testing, has some limitations because patients with PPS present biomechanical changes during the test performance and also because they are not able to undergo adjustments to its accomplishment ${ }^{41}$.

\section{FINAL REMARKS}

The management of NMDs, including PPS poses a significant challenge for both clinicians and patients. Often this problem is complicated by "paradigm paralysis and cardiorespiratory problems", which leads clinicians to follow conventional invasive protocols without considering noninvasive options and rehabilitation programs. Early detection and rehabilitation\clinical programs can have a management of such problems and prolongs quality of life.

The management of PPS requires new principles with specific attention to the factors of the vulnerability of compensatory mechanisms to injury by overuse, underuse, under oxygenation, and an inefficient use of weakened musculature. Clinicians must provide information and a balanced prescription of exercise, rest, activity, support, and intelligent accommodation to additional disability. Further studies and other analysis are needed.

\section{References}

1. Bickerstaffe A, Beelen A, Nollet F. Change in physical mobility over 10 years in post-polio syndrome. Neuromuscul Disord. 2015;25(3):225-30. doi:10.1016/j.nmd.2014.11.015

2. Esteban J. [Polio paralytic: new problems: postpolio syndrome]. Rev Esp Salud Publica. 2013; 87(5):517-22. Spanish. doi:10.4321/S1135-57272013000500010

3. Trojan DA, Cashman NR. Post-poliomyelitis syndrome. Muscle Nerve. 2005;319(1):6-19. doi:10.1002/mus.20259

4. Bach JR, Alba AS. Pulmonary dysfunction and sleep disordered breathing as post-polio sequelae: evaluation and management. Orthopedics. 1991;14(12):1329-37. doi:10.3928/0147-7447-19911201-07

5. Trojan DA, Arnold DL, Shapiro S, Bar-Or A, Robinson A, Le Cruguel JP et al. Fatigue in post-poliomyelitis syndrome: association with disease-related, behavioral, and psychosocial factors. PM R. 2009;1(5):442-9. doi:10.1016/j.pmrj.2009.03.003

6. Fischer JR; Headley J.. Post-polio breathing and sleep problems revisited. Post-Polio Health. 2004;20(2):5-7.

7. Garip Y, Eser F, Bodur H, Baskan B, Sivas F, Yilmaz O. Health related quality of life in Turkish polio survivors: impact of post-polio on the health related quality of life in terms of functional status, severity of pain, fatigue, and social, and emotional functioning. Rev Bras Reumatol. 2015. In press. doi:10.1016/j.rbre.2014.12.006

8. Silva TM, Moreira GA, Quadros AAJ, Pradella-Hallinan M, Tufik S, Oliveira ASB. Analysis of sleep characteristics in post-polio syndrome patients. Arq Neuropsiquiatr. 2010;68(4):535-40. doi:10.1590/S0004-282X2010000400011

9. Siegel H, McCutchen C, Dalakas MC, Freeman A, Graham B, Alling $D$ et al. Physiologic events initiating REM sleep in patients with the postpolio syndrome. Neurology. 1999;52(3):516-22. doi:10.1212/WNL.52.3.516

10. Laffont I, Julia M, Tiffreau V, Yelnik A, Herisson C, Pelissier J. Aging and sequelae of poliomyelitis. Ann Phys Rehabil Med. 2010;53(1):24-33. doi:10.1016/j.rehab.2009.10.002

11. Romigi A, Maestri M. Circadian fatigue or unrecognized restless legs syndrome? The post-polio syndrome model. Front Neurol. 2014;5:115. doi:10.3389/fneur.2014.00115

12. Vasconcelos OM, Prokhorenko OA, Salajegheh MK, Kelley KF, Livornese K, Olsen $\mathrm{CH}$ et al. Modafinil for treatment of fatigue in post-polio syndrome: a randomized controlled trial. Neurology. 2007;68(20):1680-6. doi:10.1212/01.wnl.0000261912.53959.b4 
13. Acler M, Bocci T, Valenti D, Turri M, Priori A, Bertolasi L. Transcranial direct current stimulation (tDCS) for sleep disturbances and fatigue in patients with post-polio syndrome. Restor Neurol Neurosci. 2013;31(5):661-8. doi:10.3233/RNN-130321

14. Gawne AC, Wells KR, Wilson KS. Cardiac risk factors in polio survivors. Arch Phys Med Rehabil. 2003;84(5):694-6. doi:10.1016/S0003-9993(02)04836-0

15. Orsini M, Souza JA, Araújo Leite MA, Teixeira S, Sá Ferreira A, Bastos VH et al. Previous acute polio and post-polio syndrome: recognizing the pathophysiology for the establishment of rehabilitation programs. Neurol Int. 2015;7(1):5452. doi:10.4081/ni.2015.5452

16. Matyja E. [Post-polio syndrome. Part II. Therapeutic management]. Neurol Neurochir Pol. 2012;46(4):372-8. Polish. doi:10.5114/ninp.2012.30270

17. Halstead LS, Rossi CD. New problems in old polio patients: results of a survey of 539 polio survivors. Orthopedics. 1985;8(7):845-50. doi:10.3928/0147-7447-19850701-06

18. Weinberg J, Borg J, Bevegård S, Sinderby C. Respiratory response to exercise in postpolio patients with severe inspiratory muscle dysfunction. Arch Phys Med Rehabil. 1999;80(9):1095-100. doi:10.1016/S0003-9993(99)90067-9

19. Dolmage TE, Avendano MA, Goldstein RS. Respiratory function during wakefulness and sleep among survivors of respiratory and non-respiratory poliomyelitis. Eur Respir J. 1992;5(7):864-70.

20. Lane DJ, Hazleman B, Nichols PJR. Late onset respiratory failure in patients with previous poliomyelitis. Q J Med. 1974;43(172):551-68.

21. Dean E, Ross J, Road JD, Courtenay L, Madill KJ. Pulmonary function in individuals with a history of poliomyelitis. Chest. 1991;100(1):118-23. doi:10.1378/chest.100.1.118

22. Lira CA, Minozzo FC, Sousa BS, Vancini RL, Andrade MS, Quadros AA et al. Lung function in post-poliomyelitis syndrome: a cross-sectional study. J Bras Pneumol. 2013;39(4):455-60. doi:10.1590/S1806-37132013000400009

23. Ward NS, Hill NS. Pulmonary function testing in neuromuscular disease. Clin Chest Med. 2001;22(4):769-81. doi:10.1016/S0272-5231(05)70065-4

24. Midgren B. Lung function and clinical outcome in postpolio patients: a prospective cohort study during 11 years. Eur Respir J. 1997;10(1):146-9. doi:10.1183/09031936.97.10010146

25. Boitano LJ. Management of airway clearance in neuromuscular disease. Respir Care. 2006;51(8):913-22.

26. Bach JR, Gonçalves MR, Hon A, Ishikawa Y, De Vito EL, Prado F et al. Changing trends in the management of end-stage neuromuscular respiratory muscle failure: recommendations of an international consensus. Am J Phys Med Rehabil. 2013;92(3):267-77. doi:10.1097/PHM.0b013e31826edcf1

27. Wolfe LF, Joyce NC, McDonald CM, Benditt JO, Finder J. Management of pulmonary complications in neuromuscular disease. Phys Med Rehabil Clin N Am. 2012;23(4):829-53. doi:10.1016/j.pmr.2012.08.010
28. Bach JR, Bakshiyev R, Hon A. Noninvasive respiratory management for patients with spinal cord injury and neuromuscular disease. Tanaffos. 2012;11(1):7-11.

29. Orsini M, Lopes AJ, Menezes SL, Oliveira AB, Freitas MR, Nascimento OJ et al. Current issues in the respiratory care of patients with amyotrophic lateral sclerosis. Arq Neuropsiquiatr. 2015;73(10):873-6. doi:10.1590/0004-282X20150132

30. Kralingen KW, Ivanyi B, Keimpema AR, Venmans BJ, Visser M, Postmus PE et al. Sleep complaints in postpolio syndrome. Arch Phys Med Rehabil. 1996;77(6):609-11. doi:10.1016/S0003-9993(96)90304-4

31. Steljes DG, Kryger MH, Kirk BW, Millar TW. Sleep in postpolio syndrome. Chest. 1990;98(1):133-40. doi:10.1378/chest.98.1.133

32. Bhat S, Gupta D, Chokroverty S. Sleep disorders in neuromuscular diseases. Neurol Clin. 2012;30(4):1359-87. doi:10.1016/j.ncl.2012.08.010

33. Aboussouan LS. Sleep-disordered breathing in neuromuscular disease. Am J Respir Crit Care Med. 2015;191(9):979-89. doi:10.1164/rccm.201412-2224C

34. Kang JH, Lin HC. Comorbidity profile of poliomyelitis survivors in a Chinese population: a population-based study. J Neurol. 2011;258(6):1026-33. doi:10.1007/s00415-010-5875-y

35. Greenland P, Alpert JS, Beller GA, Benjamin EJ, Budoff MJ, Fayad ZA et al. 2010 ACCF/AHA guideline for assessment of cardiovascular risk in asymptomatic adults: a report of the American College of Cardiology Foundation/American Heart Association Task Force on Practice Guidelines. J Am Coll Cardiol. 2010;56(25):e50-103. doi:10.1016/j.jacc.2010.09.001

36. Stöllberger C, Blazek G, Wegner C, Finsterer J. Neurological comorbidity affects prognosis in left ventricular hypertrabeculation/noncompaction. Heart Lung. 2012;41(6):594-8. doi:10.1016/j.hrtlng.2012.03.002

37. Nollet F, Beelen A, Sargeant AJ, Visser M, Lankhorst GJ, Jong BA. Submaximal exercise capacity and maximal power output in polio subjects. Arch Phys Med Rehabil. 2001;82(12):1678-85. doi:10.1053/apmr.2001.27390

38. Kriz JL, Jones DR, Speier JL, Canine JK, Owen RR, Serfass RC. Cardiorespiratory responses to upper extremity aerobic training by postpolio subjects. Arch Phys Med Rehabil. 1992;73(1):49-54.

39. Dean E, Ross J. Effect of modified aerobic training on movement energetics in polio survivors. Orthopedics. 1991;14(11):1243-6.

40. Voorn EL, Gerrits KH, Koopman FS, Nollet F, Beelen A. Determining the anaerobic threshold in postpolio syndrome: comparison with current guidelines for training intensity prescription. Arch Phys Med Rehabil. 2014;95(5):935-40. doi:10.1016/j.apmr.2014.01.015

41. Vreede KS, Henriksson J, Borg K, Henriksson M. Gait characteristics and influence of fatigue during the 6 -minute walk test in patients with post-polio syndrome. J Rehabil Med. 2013;45(9):924-8. doi:10.2340/16501977-1209 